\title{
PREGNANCY OUTCOME IN FEMALES WITH HIGH BODY MASS INDEX
}

\author{
SADIA ZAHOOR, TAHIRA MALIK, SADIA YOUNUS, AALIA TAYYBA, \\ ZILL E HUMA, SAIMA AZHAR \\ Department of Obstetrics \& Gynaecology, Sheikh Zayed Hospital, Rahim Yar Khan
}

\begin{abstract}
Objective: To determine the various pregnancy outcomes in females with high pre pregnancy Body Mass Index (BMI).

Methods: It was descriptive case series at Sheikh Zayed Hospital, Rahim Yar Khan. Duration of the study was from 30-06-2016 to 31-12-2017. In the present study, pregnant females with age of gestation less than 12 weeks presenting with their first ante natal visit falling in the age range of 20-40 years having pre pregnancy BMI $>25 \mathrm{~kg} / \mathrm{m}^{2} \mathrm{were}$ included. Then these cases were followed for their whole pregnancy to look for various outcomes.

Results; In the present study there were 150 subjects enrolled with high pre pregnancy BMI. Mean age of the participants was $28.41 \pm 4.67$ year and mean BMI was $28.31 \pm 3.57 \mathrm{~kg} / \mathrm{m}^{2}$. Regarding various outcome the most common one was $\mathrm{C}$ section which was seen in $42(28 \%)$ of the cases, followed by PIH seen in $35(23.34 \%)$ of the cases, while pregnancy remained uneventful in only 21 (14\%) of the cases.

Conclusion: High pre pregnancy BMI leads to various complication, which are seen in almost 8 out of 10 cases and the most common one is $\mathrm{C}$ section.
\end{abstract}

Key words: BMI, C section, PIH

How to cite this article: Zahoor S, Malik T, Younas S, Tayyba A, Huma Z, Azhar S. Pregnancy outcome in females with high BMI. Pak Postgrad Med J 2020;31(3): 159-162

This is an Open Access article distributed under the terms of the Creative Commons Attribution License (http://creativecommons.org/licenses/by/3.0), which permits unrestricted use, distribution, and reproduction in any medium, provided the original work is properly cited.

DOI: http://doi.org/10.51642/ppmj.v31i03.357

Correspondence to: Tahira Malik, Associate

Professor,

Department of Obstetrics \& Gynaecology, Sheikh

Zayed Hospital, Rahim Yar Khan, Pakistan.

Email:dr.aftabanwar@gmail.com

\section{INTRODUCTION}

Pre-pregnancy obesity is not uncommon and has emerged as a great obstetric health concern globally in the recent era. It's number is rising as overall incidence of obesity is rising. Local data is lacking but the data from Australia has revealed this prevalence in $34 \%$ of the cases. ${ }^{1}$

The data has shown that both pre pregnancy obesity and rapid gain of weight during the pregnancy both can impact the pregnancy outcome in various ways and can result in a wide variety of outcomes. ${ }^{2}$

The most consistently developed maternal complications during pregnancy and delivery are pregnancy induced hypertension (PIH), preeclempsia, venous thromboembolism, gestational diabetes mellitus (GDM), labor induction, postpartum hemorrhage, miscarriage, urinary tract infections and effects on mode of deliveries like instrumentation and/or surgery. Maternal overweight is related to a higher risk of cesarean section (CS) deliveries and a higher incidence of anesthetic and postoperative complications in these deliveries. ${ }^{3-5}$ Obese women are also said to experience increased rates of puerperal infection and decreased rates of breastfeeding initiation or continuation.

\section{METHODS}

This descriptive case series was conducted during 0106-2016 to 31-12-2018 at Sheikh Zayed Hospital, Rahim Yar Khan in which the cases were selected via on probability consecutive sampling. The pregnant females with age of gestation less than 12 weeks presenting with their first ante natal visit falling in the age range of 20-40 years having pre pregnancy BMI $>25 \mathrm{~kg} / \mathrm{m}^{2}$ were included. The cases with BMI less than or equal to 25 , those having end stage renal or hepatic failure and those with prior history of GDM, pregnancy induced hypertension were excluded from this study. Then these cases were followed monthly for various pregnancy outcomes. 
SPSS 22.0 was used for data analysis and frequency and percentages were calculated for categorical data and mean and standard deviation for quantitative data.

\section{RESULTS}

In the present study there were 150 subjects enrolled with high pre pregnancy BMI. Mean age of the participants was $28.41 \pm 4.67$ year and mean BMI was $28.31 \pm 3.57 \mathrm{~kg} / \mathrm{m}^{2}$ as shown in table I. There wee 24 $(16 \%)$ cases graduated and $108(72 \%)$ were from rural population (table II). Regarding various outcome the most common one was $\mathrm{C}$ section which was seen in $42(28 \%)$ Of the cases, followed by PIH seen in 35 $(23.34 \%)$ of the cases. GDM was seen in $24(16 \%)$, pre term labor in $20(13.33 \%)$ and miscarriage in 8 $(5.33 \%)$ of subjects while pregnancy remained uneventful in only $21(14 \%)$ of the cases as shown in table III.

Table I. Demographics $(\mathrm{n}=150)$

\begin{tabular}{lcc}
\hline \multicolumn{1}{c}{ Variables } & Mean \pm SD & Range \\
\hline Age & $28.41 \pm 4.67$ & $20-40$ \\
BMI & $28.31 \pm 3.57$ & $26-34$ \\
Gravida & $4.31 \pm 2.19$ & $0-10$ \\
Parity & $3.79 \pm 1.23$ & $0-6$ \\
\hline
\end{tabular}

Table II. Study variables $(\mathrm{n}=150)$

\begin{tabular}{llcc}
\hline \multicolumn{2}{c}{ Variables } & Number & $\%$ \\
\hline Educational & Graduate & 24 & 16 \\
status & Undergraduate & 126 & 84 \\
Residential & Rural & 108 & 72 \\
status & Urban & 42 & 28 \\
\hline
\end{tabular}

Table III. Pregnancy outcome $(n=150)$

\begin{tabular}{lcc}
\hline \multicolumn{1}{c}{ Variables } & Number & $\%$ \\
\hline C section & 42 & 28 \\
PIH & 35 & 23.34 \\
GDM & 24 & 16 \\
Preterm labor & 20 & 13.33 \\
Miscarriage & 8 & 5.33 \\
Uneventful & 21 & 14 \\
Mortality & 0 & 0 \\
\hline
\end{tabular}

\section{DISCUSSION}

Obesity is one of the morbid entities and can predispose to various other complications of the pregnancy. Gestational DM, pregnancy induced HTN, miscarriages and difficulty in delivery are the cardinal ones. Its incidence is highest in the developed countries and seen in around $20 \%$ of the cases in the United States; the data in Pakistan is lacking. ${ }^{6-8}$

The findings of our study revealed that regarding various outcome the most common one was $\mathrm{C}$ section which was seen in 42 (28\%) Of the cases, followed by PIH seen in $35(23.34 \%)$ of the cases. GDM was seen in $24(16 \%)$, pre term labor in $20(13.33 \%)$ and miscarriage in $8(5.33 \%)$ of subjects while pregnancy remained uneventful in only $21(14 \%)$ of the cases
These results were comparable with the findings of the studies done in the past where high degree of events were noted during the course of pregnancy in females with pre pregnancy obesity. The results from the study done by Khuhro BN et al stated that the most common complication in their study was also C section which was observed in $28 \%$ of the cases and it was followed by gestation DM in $15 \%$, pre-term labor in $15 \%$ of the subjects. While pregnancy induced HTN was seen in $8 \%$ and miscarriages in only $5 \%$ of the cases. ${ }^{9}$

This findings was also supported by the case series of Vinturache A, where same complication was observed and even higher numbers were noted and was seen in $46 \%$ of the cases with BMI $>25 \mathrm{~kg} / \mathrm{m}^{2} .{ }^{10}$

In another study by Ali HS et al they found this $\mathrm{C}$ section in $48 \%$ of the pregnant females with high BMI and found GDM in less than $2 \%$ of their cases while in present study this was noted in $16 \%$ of the subjects. ${ }^{11}$ PIH. Riaz S et al found PIH in $23 \%$ of subjects which was $13.33 \%$ in our study. ${ }^{12}$

\section{CONCLUSION}

High pre pregnancy BMI leads to various complication, which are seen in almost 8 out of 10 cases and the most common one is $\mathrm{C}$ section.

\section{ETHICAL APPROVAL}

The study was approved from Institutional Review Board of Sheikh Zayed Medical College/Hospital, Rahim Yar Khan.

\section{REFERENCES}

1. Callaway LK, Prins JB, Chang AM, McIntyre HD. The prevalence and impact of overweight and obesity in an Australian population. Med J Aust. 2006;184(2):56-59.

2. Uzma S, Anwer A, Sultana N. Maternal complications in obese and normal weight pregnant women. Ann Pak Isnt Med Sci. 2014;10(2):84-88.

3. Flenady V, Koopmans L, Middleton P, Frøen JF, Smith GC, Gibbons K, et al. Major risk factors for stillbirth in high-income countries: a systematic review and meta-analysis. Lancet. 2011;377(9774):1331-1340.

4. Baron CM, Girling LG, Mathieson AL, Menticoglou SM, Seshia MM, Cheang MS, et al. Obstetrical and neonatal outcomes in obese parturients. J Matern Fetal Neonatal Med. 2010;23(8):906-913.

5. Arrowsmith S, Wray S, Quenby S. Maternal obesity and labour complications following induction of labour in prolonged pregnancy. Int $\mathbf{J}$ Obstet Gynaecol. 2011;118(5):578-588.

6. Rasmussen SA, Chu SY, Kim SY, Schmid CH, Lau J: Maternal obesity and risk of neural tube defects: a metaanalysis. Am J Obstet Gynecol. 2008, 198 (6): 611-619. 
7. Flenady V, Koopmans L, Middleton P, Frøen JF, Smith GC, Gibbons K, et al. Major risk factors for stillbirth in high-income countries: a systematic review and meta-analysis. Lancet. 2011;377 (9774):1331-1340.

8. Chu SY, Kim SY, Lau J, Schmid CH, Dietz PM, Callaghan WM, Curtis KM: Maternal obesity and risk of stillbirth: a metaanalysis. Am J Obstet Gynecol. 2007, 197 (3): 223-228. Khuhro BN, Husaain R. Effects of high body mass index on fetomaternal outcome. Pak J Med Dent. 2013;1(1):12-20.

9. Khuhro BN, Husaain R. Effects of high body mass index on fetomaternal outcome. Pak J Med Dent. 2013;1(1):12-20.

10. Vinturache A, Moledina N, McDonald S, Slater D, Tough S. Pre-pregnancy body mass index (BMI) and delivery outcomes in a Canadian population. BMC Pregnancy Childbirth. 2014;14:422-423.
11. Ali HS, Lakhani N. Effect of obesity and its outcome among pregnant women. Pak J Med Sci. 2011;27(5):1126-1128.

12. Riaz S, Habib S, Jabeen A. Frequency of maternal mortality and morbidity in pregnancy-induced hypertension. J Ayub Med Coll Abbottabad. 2011;23(4):61-63.
AUTHOURS CONTRIBUTIONS
SZ: $\quad$ Concept, Design Manuscript Writing
TM, SY: Data Collection
AT Data analysis and interpretation
ZH: Statistical Analysis
SA: Discussion 